\title{
Review Paper: Indicators of Life Recovery after Disasters and Emergencies
}

\author{
Maryam Nakhaei ${ }^{1 *}$, Hamid Reza Khankeh ${ }^{2,3}$, Fatemeh Ghasemi ${ }^{4}$ \\ 1. Birjand Health Qualitative Research Center, Birjand University of Medical Sciences, Birjand, Iran. \\ 2. Department of Nursing, University of Social Welfare \& Rehabilitation Sciences, Tehran, Iran. \\ 3. Department of Clinical Science and Education, Karolinska Institutet, Solnavägen, Solna, Sweden. \\ 4. Birjand Valiasr Hospital, Birjand, Iran.
}

Crtation: Nakhaei M, Khankeh HR, Ghasemi F. Indicators of life recovery after disasters and emergencies. Health in Emergencies and Disasters Quarterly. 2016; 1(3):121-124. http://dx.crossref.org/10.15412/J.HDQ.09010301

d. $]^{:}$: http://dx.crossref.org/10.15412/J.HDQ.09010301

Article info:

Received: 16 Nov. 2015

Accepted: 01 Mar. 2016

\section{Keywords:}

Accidents, Calamities, Disasters, Recovery, Life recovery, Indicator

\section{ABSTRACT}

Recovery is a part of disaster management cycle during which repair and reconstruction takes place, and individuals, groups, and communities retake what they have lost and ideally the risk of future incidents reduces. Life recovery is a subjective and multidimensional issue influenced by various factors, whereas valid measurable indicators in evaluating the recovery after disasters are helpful. This article considers the related texts with the aim of reviewing the indicators of recovery after disasters. The examined issues are basics of recovery, recovery in the form of process, as well as components and dimensions of recovery.

\section{Introduction}

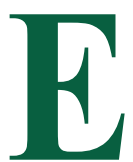

mergencies and disasters, natural or manmade, have destructive impacts and consequences that may have deep and clear effects or uncharted results [1]. However, they are controllable and manageable through intelligent planning. Effective management at the time of disasters depends on anticipating and identifying the problems resulting from disasters and considering the necessary facilities at proper time and place [2, 3]. Although mitigation and preparedness plans reduce the vulnerability and impacts, and the response lessen human and proper losses with the best of planning for disaster management, there will always be degrees of environmental and financial damages. Dam- age to infrastructures, destruction of economic and social systems, and physical and psychological health consequences that require reconstruction, recovery, repair and return to functional conditions [2]. These activities are managed within the recovery management process.

The concept of recovery seems to have a clear and specific meaning; however, in the literature, this concept has been considered as an approach, model, philosophy, paradigm, and so on. Two principal viewpoints exist regarding this concept: one focuses on specific clinical and social dimensions and has tangible nature and the other asserts tangible and internal and subjective dimensions [4-6].

\section{* Corresponding Author:}

Maryam Nakhaei, PhD

Address: Birjand Health Qualitative Research Center, Birjand University of Medical Sciences, Birjand, Iran

E-mail: maryamnakhaee.mn@gmail.com 


\section{Recovery in Emergencies and Disasters}

Disaster recovery has also been considered and defined from different viewpoints [7] and has been described as a goal, a phase of disaster management and/or a process

Although recovery is a part of the disaster management cycle, compared with other stages of that cycle, it has received less attention as regards to theoretical and operational viewpoint [7], and its concepts have extensive overlap with concepts such as rehabilitation, reconstruction, restoration, and so on $[7,8]$.

In the disaster management, the recovery is defined as the stage following the response stage. However, it is difficult to pinpoint a line where the response ends and the recovery begins. A definite time cannot be suggested for rehabilitation, reconstruction, and recovery because these stages are interconnected. In fact, the response stage has not yet ended when the recovery and evaluation phase begins [2,9]. Certainly, as the activities of the recovery phase are more varied and different individuals, groups, and organizations are involved, this phase is least studied and least organized and its execution is more difficult than all other stages [2, 9-11].

The Federal Emergency Management Agency (FEMA) states that recovery continues until all systems return to their normal or better condition [8]. International Strategy for Disaster Reduction (ISDR) defines recovery as "Decisions and actions taken after a disaster with a view to restoring or improving the pre-disaster living conditions of the stricken community, while encouraging and facilitating necessary adjustments to reduce disaster risk." [12]. Several definitions of recovery have focused on structural repair or reconstruction and to distinguish between short-term and long-term recovery. Scientists such as Nigg have considered recovery beyond reconstruction of physical environment and preferably as a social process influenced by conditions before and after the incident [13].

\section{Life Recovery after Disasters; A Process}

Although some definitions attend to returning to preincident conditions, in some other definitions it is argued that since after a disaster the community experience some changes, therefore, a return to conditions prior to the incident does not happen, instead, the recovery is described as achieving an stable condition and recovery period is considered as an opportunity for renewal and upgrade [14]. In the literature review, it has become clear that life recovery is assumed as a individually long time and ongoing process.

Initial studies have described the recovery as a fourphased sequential description (emergency period; restoration period; replacement and reconstruction period; and commemorative, betterment, and developmental reconstruction period $[8,15]$.

In Hyogo Life Recovery Project, with the aim of determining the dimensions and long-term processes of recovery, it was indicated that two different processes, damage alleviation and event evaluation, influenced life recovery outcomes. Damage alleviation is a process that in short term alleviates the impacts caused by damages from earthquake, losses, and or stresses with activities like housing construction, stress management, and livelihood recovery. Through event evaluation, social ties and community rebuilding efforts directly or indirectly facilitated the reframing of disaster experiences into positive narratives. [16].

Some studies about recovery have attended to life recovery of survivors in different time periods, such as Kimora study (2009) in which it was indicated that after the accident, the survivors pass through 4 time sequence stages including disorientation, acceptance of new reality, utopia, and reentry to everyday life [17]. Although there may exist certain differences in different societies, there are common elements in the time sequence and the arrangement of this process.

Also, $\mathrm{Xu}$ (2012) described the recovery process in two phases of transitional, and comprehensive recovery. The transitional recovery takes place immediately after the incident by taking the recovery's short-term steps and also by preparation for comprehensive recovery [18].

In addition to determining the path of recovery process, the mechanisms for accessing the recovery outcomes are among the most important issues for recovery and have been considered in different studies.

\section{Indicators of Recovery}

There is no consensus over the meaning of recovery, how to evaluate it, or the characteristics of a successful recovery. In the past decade, there have been efforts to design a systematic model to explain and measure the recovery process after disasters $[14,19]$. The scarcity of measurable indicators and the focus of studies on case studies have limited the possibility to compare the outcomes between different incidents and their follow up 
$[14,19,20]$. For this purpose, in various studies, efforts have been made to identify and examine the components and dimensions of life recovery after disasters and to design indicators for measuring the outcomes.

In Hyogo life recovery Project, to determine the dimensions and long-term processes of life recovery, seven critical element of housing, social ties, community rebuilding, physical and psychological health, preparedness, economic and financial situation, and relation to government have been identified [16].

In Sakamoto study (2009) emphasized social ties and it was indicated that the priority of indicators is different in various communities. In addition to the elements defined in the Hyogo project, Sakamoto introduced religion as an effective component [21]. Disaster life recovery is a subjective issue that could be different as regards to different social values and life conditions. Therefore, social dimensions and social capital have important roles in recovery [17, 21, 23].

Abramson study (2010) was conducted to develop an operational measure of individual recovery and determined, and a stable housing, economic stability, physical health, mental health, and social role adaptation have been considered as important factors [20]. In addition, Dwyer study (2014) considered structural and non-structural recovery at community level. The components considered in this study include community planning and capacity building, economic recovery, health and social services recovery, housing recovery, recovery of infrastructures, recovery of natural and cultural resources, public information and warning, and operational coordination [19].

Several studies have attended to assessment of recovery in one dimension; however, the comprehensive recovery planning that is referred to as "long-term recovery" should consider all physical and non-physical needs of damaged areas. Recovery would be effective when it considers the social, cultural, religious, and economic dimensions. And as long as all needs of a damaged community have not been met, the community would not be free of the incident's consequences, and recovery would not be complete [2, 9, 24]. Similarly, Khankeh study (2013) has discussed the comprehensive recovery plan and consideration of various elements of physical, psychological, mental health, and social and livelihood issues [24].

Design of the recovery indicators, especially at the individual level, is among the important issues considered not only by planners and policymakers but also by practitioners specialized in the field of recovery after accidents and disasters. These indicators can also be employed as tools for determining the direction and the degree of progress prior to and after the incident.

\section{Conclusion}

Disaster recovery is a part of the disaster and emergency management cycle, during which, repair and reconstruction takes place and individuals, groups, and communities retake what they have lost, and ideally, the future accidents risks is minimized.

Disaster recovery activities can be divided into shortterm and long-term activities. The short-term phase begins immediately after the incident and can be considered as the transitional stage from response phase to recovery one. These activities are carried out with the aim of preserving the vital support systems. However, community's long-term activities of renovation and rehabilitation aim to reach normal conditions or even improved levels and need a thorough planning and much coordination because recovery provides specific opportunities, though limited, for renovating the structures more resilient than they were before. The plan for recovery after disasters should be proportionate to long-term objectives of the community and be based on principles of sustainable development. A good recovery is a comprehensive recovery and is planned with a look at the communities' interests and by considering the principles of sustainability.

Therefore, disaster recovery can be defined as a process to preserve and maintain, to renew structure, and to reshape the physical, social, and economic and natural environment through planning before and implementing after the incident. In this definition, outcomes with sustainable recovery were mentioned, also it was indicated that individuals, groups, and organizations are affected differently by disasters and as a result, the complete recovery process is not necessarily linear and is influenced by social parameters. Therefore, recovery after disasters does not take place in the same shape and speed in all individuals.

\section{Acknowledgements}

The current research hasn't received any financial support.

\section{Conflict of Interests}

The authors declared no conflict of interests. 


\section{References}

[1] Guba-Sapir D, Hoyois P, Below R. Annual disaster statistical review 2014: the numbers and trends. Belgium, Brussels: Université catholique Louvain-la-Neuve; 2015. Available from: http://www.cred.be/sites/default/files/ADSR_2014.pdf

[2] Coppola DP. Introduction to international disaster management. $3^{\text {rd }}$ ed. Oxford: Elsevier Inc; 2015.

[3] Khankeh HR, Khorasani-Zavareh D, Johanson E, Mohamm madi R, Ahmadi F, Mohammadi R. [Disaster health-related challenges and requirements: a grounded theory study in Iran (Persian)]. Prehospital Disaster Medicine. 2011; 26(3):1-8

[4] Schrank B, Slade M. Recovery in psychiatry. Psychiatric Bulletin. 2007; 31(9):321-25. doi: 10.1192/pb.bp.106.013425

[5] Roberts G. The rediscovery of recovery: open to all. Cutting Edge Psychiatry in Practice. 2011; 1(3):115-21.

[6] Shepherd G, Boardman J, Slade M. Making recovery a reality. London: Sainsbury Center for Mental Health; 2008.

[7] Rodríguez H, Quarantelli EL, Dynes RR. Handbook of disaster research. New York: Springer Science; 2007.

[8] Phillips BD. Disaster recovery. Routledge: Taylor \& Francis Group; 2009 .

[9] Pinkowski J. Disaster management handbook. Routledge: Taylor \& Francis Group; 2008.

[10] Veenema TG. Disaster nursing \& emergency preparedness for chemical, biological \& radiological terrorism \& other hazards. $2^{\text {nd }}$ ed. New York: Springer Publishing Company; 2007.

[11] Shaw R. Disaster recovery-used or misused development opportunity. Tokyo: Springer; 2014.

[12] United Nations. International strategy for disaster reduction. UNISDR Terminology on Disaster Risk Reduction. Geneva: United Nations; 2009.

[13] Nigg JM. Disaster recovery as a social process. Wellington after the quake: the challenge of rebuilding. Wellington, New Zealand: The Earthquake Commission; 1995.

[14] Joakim EP, Wismer SK. Livelihood recovery after disaster Development in Practice. 2015; 25(3):401-18.

[15] Blanco H, Alberti M, Olshansky R, Chang S, Wheeler SM, Randolph J. Shaken, shrinking, hot, impoverished and informal: emerging research agendas in planning. Progress in Planning. 2009; 72(4):195-250.

[16] Tatsuki Sh. Long-term life recovery processes among survivors of the 1995 Kobe earthquake: 1999, 2001, 2003, and 2005 life recovery social survey results. Journal of Disaster Research. 2007; 2(6):484-501.

[17] Kimura R. Recovery and reconstruction calendar. Journal of Disaster Research. 2007; 2(6):465-74.

[18] Xu J, Lu Y. Meta-synthesis pattern of post-disaster recovery and reconstruction: based on actual investigation on 2008 Wenchuan earthquake. Natural Hazards. 2012; 60(2):199-222.

[19] Dwyer C, Horney J. Validating indicators of disaster recovery with qualitative research. PLOS Currents Disasters. 2014; 6. doi: 10.1371/currents.dis.ec60859ff436919e096d51ef7d50736f
[20] Abramson DM, Stehling-Ariza T, Park YS, Walsh L, Culp D. Measuring individual disaster recovery: a socio-ecological framework. Disaster Medicine and Public Health Preparedness. 2010; 4(1):46-54.

[21] Sakamoto M, Yamori K. A Study of life recovery and social capital regarding disaster victims: a case study of Indian Ocean Tsunami and central Java earthquake recovery. Journal of Natural Disaster Science. 2009; 31(2):13-20.

[22] Cox RS, Perry KM. Like a fish out of water: reconsidering disaster recovery and the role of place and social capital in community disaster resilience. American Journal of Community Psychology. 2011; 48(3-4):395-411. doi: 10.1007/s10464011-9427-0

[23] Alipour F, Khankeh HR, Fekrazad H, Kamali M, Rafiey $\mathrm{H}$, Sarrami Foroushani $\mathrm{P}$, et al. Challenges for resuming normal life after earthquake: a qualitative study on rural areas of Iran. PLoS Current. 2014; 6. doi: 10.1371/currents.dis.b4e84b942500e2f8f260f3471b7ee815

[24] Khankeh H, Nakhaei M, Masoumi G, Hosseini M, ParsaYekta Z, Kurland L, et al. Life recovery after disasters: a qualitative study in the Iranian context. Prehospital Disaster Medicine. 2013; 28(6):573-79. 